\title{
ISOKINETIC AND FUNCTIONAL EVALUATION OF DISTAL BICEPS RECONSTRUCTION USING THE MAYO MINI-DOUBLE ROUTE TECHNIQUE
}

José Carlos Garcia Júnior ${ }^{1}$, Carlos Daniel Candido de Castro Filho², Tadeu Fujita de Castro Mello², Rodrigo Antunes de Vasconcelos ${ }^{3}$, José Luís Amim Zabeu4, Jesely Pereira Myrrha Garcia ${ }^{5}$

\section{ABSTRACT}

Objective: To evaluate the functional outcome among patients with distal biceps injuries who were operated using the Mayo mini-double route technique, with a minimum follow-up of six months after surgery, through digital isokinetic dynamometry, goniometry and subjective scores in order to establish objective and subjective improvement patterns and discuss the effectiveness of the procedure. Methods: Nine patients who underwent surgery to treat distal biceps injury were evaluated by means of Cybex digital dynamometry using an angular velocity of $30 \% \mathrm{~s}$ with five repetitions and $120 \%$ s with 15 repetitions, in comparison with the uninjured side. DASH (Disabilities of the arm, shoulder and hand), Mayo elbow score and conventional goniometry were also used. Results: Digital dynamometer showed that using the angular velocity of $30 \% \mathrm{~s}$ with five repetitions, there was an average flexion deficit of $9.6 \%$ and an average supination deficit of $-28.97 \%$. Using an angular velocity of $120 \%$ with fifteen repetitions, the average flexion deficit was $4.43 \%$ and the average supination deficit was $-24.1 \%$. Conclusions: The loss of flexion followed the pattern already shown in the literature. However, in our series, there were supination strength gains, possibly due to the strict rehabilitation protocol. The technique used in this study was safe and low-cost, with few complications and good functional results.

Keywords - Tendon Injuries; Tendons/surgery; Treatment Outcome

\section{INTRODUCTION}

Avulsion of the distal tendon of the brachial biceps is an uncommon injury that accounts for around 3\% of all injuries of the biceps tendon. It mainly affects the dominant arm, in active middle-aged men (in their fifth and sixth decades of life) ${ }^{(1)}$.

The brachial biceps is a muscle with insertion in the radial tuberosity and, because of this anatomical position, its main biomechanical function is to perform supination of the forearm. It is also considered to be secondary flexor of the elbow. Elbow flexion is optimized through supination, and the maximum torque with the elbow is at flexion of between $90^{\circ}$ and $110^{\circ(2-4)}$.

The injury mechanism is usually traumatic, and injury occurs when an eccentric load of 400 newtons or more is applied to the forearm with the elbow at $90^{\circ(4-6)}$. Tendons with degenerative characteristics secondary to bursopathy and conditions that affect collagen metabolism may also be factors predisposing towards this type of lesion ${ }^{(2,7-11)}$.

The clinical condition comprises sudden acute pain in the region of the cubital fossa that persists for a few hours, followed by a less intense pain that may

1 - Shoulder and Elbow Surgeon in the Advanced Study Center for Orthopedics and Neurosurgery, São Paulo, SP, Brazil.

2 - Resident in the Orthopedics and Traumatology Clinic, Celso Pierro Hospital and Maternity Hospital, PUC/Campinas, Campinas, SP, Brazil.

3 - Physiotherapist and Coordinator of CEAFE, Wilson Mello Institute, Campinas, SP, Brazil.

4 - Physician in the Orthopedics and Traumatology Clinic, Celso Pierro Hospital and Maternity Hospital, PUC/Campinas, Campinas, SP, Brazil.

5 - Physiotherapist in the Advanced Study Center for Orthopedics and Neurosurgery, São Paulo, SP, Brazil.

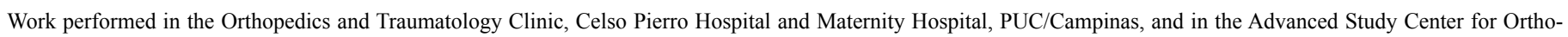
pedics and Neurosurgery, São Paulo, SP.

Correspondence: Av. Macuco 726, cj. 1606, 04523-001 São Paulo, SP. E-mail: josecarlos@especialistadoombro.com.br

Work received for publication: December 20, 2011; accepted for publication: March 15, 2012.

The authors declare that there was no conflict of interest in conducting this work 
continue for some days or even months. In the physical examination, edema may be observed in the same region, accompanied by ecchymosis ${ }^{(1-21)}$.

The belly of the biceps retracts proximally to produce a distal defect, thus forming the inverted Popeye sign, which is enough to suggest that a lesion is present ${ }^{(1,5,12,14,16,17)}$. Loss of movement is not a significant characteristic, but loss of strength occurs, particularly for performing supination of the forearm, with a deficit of around $40 \%$. Since the loss of flexion strength is around $30 \%$, it may go unnoticed by the patient $^{(2-4,8,12,13,18)}$.

The diagnosis is clinical, and the hypothesis of the lesion can be confirmed by means of imaging examinations (ultrasonography and magnetic resonance $)^{(1-21)}$.

The treatment for ruptures of the distal tendon on the biceps can be conservative or surgical ${ }^{(1-21)}$. With conservative treatment, the loss of muscle strength for supination is maintained $\mathrm{d}^{(1,2,8,18)}$. This suggests that surgical repair might be more indicated for athletes, patients with high functional demands and patients who do not accept loss of strength or esthetic deformity ${ }^{(1,4,7)}$.

Surgical repair may attain a muscle strength level similar to that of the unaffected contralateral $\operatorname{limb}^{(2,3,6,8-12,20)}$. Studies on surgical treatment have demonstrated high levels of muscle strength and resistance for the elbow flexors and forearm supinators after surgical repair ${ }^{(2,3,6,8-17,20)}$.

The first technique described was lesion repair by means of a single anterior incision. However, reports in the literature have demonstrated complications such as injury to the radial artery, median nerve and posterior interosseous nerve ${ }^{(6,8-17,19-21)}$.

In 1961, Boyd and Anderson ${ }^{(3)}$ introduced a double-incision technique in order to minimize these risks. However, their technique may have the complication of proximal radioulnar synostosis ${ }^{(3,4,8-18,20,21)}$. More recently, Morrey et $a l^{(22)}$ modified the original technique using a mini-double route, thereby achieving lower complication rates ${ }^{(13-15,20)}$.

Conservative treatment is advised in cases of sedentary individuals or elderly people who do not need to perform activities requiring forearm supination strength and elbow flexion in their daily activities and in cases in which the esthetic deformity is acceptable to the patient ${ }^{(8,16,17,20)}$.
When proximal retraction occurs, use of grafts is indicated in order to perform tenodesis ${ }^{(6,8-17,19-21)}$. The grafts used generally come from the fascia lata, radial flexor of the carpus, semitendinosus or calcaneal tendon $^{(8-17,19-21)}$.

To assess muscle strength after the operation, measurements on the moment of force and torque at constant velocity can be made using the isokinetic test $^{(8,16,17,20)}$. This assessment can be done using an isokinetic digital dynamometer, which can also assist in rehabilitation, as well as identifying muscle deficits, particularly during the postoperative rehabilitation activity phase $^{(8,16,17,20)}$.

Few studies objectively evaluating the functional results from the surgical procedures (using digital dynamometry) are available in the worldwide literature. The existing studies present small numbers of patients and a variety of surgical techniques ${ }^{(17)}$.

The objective of the present study was to evaluate the functional results from using the original Mayo mini-double route technique for the biceps, with a minimum of six months of postoperative follow-up, using isokinetic digital dynamometry, DASH (Disabilities of the Arm, Shoulder and Hand), Mayo Elbow Score and goniometry, in order to establish objective improvement patterns and discuss the effectiveness of the procedure.

\section{METHODS}

This was a retrospective cross-sectional study. Between April 2006 and July 2011, 18 patients with lesions of the distal biceps underwent operations, of which 17 underwent the Mayo mini-double route technique with transosseous sutures (Figures 1, 2, 3 and 4). Of these patients, nine underwent a digital dynamometry examination using $\mathrm{Cybex}^{\circledR}$ and were analyzed in this study.

Eight patients who underwent operations by means of the Mayo mini-double route technique did not undergo this examination: three because less than six months had passed since their surgery; one because the same lesion was presented on the contralateral side; and four who were unable to come back for the examination.

The patient who was not operated using this technique was a professional bodybuilder and presented great retraction, with injury more than two years earlier. The surgery that was performed lowered the 


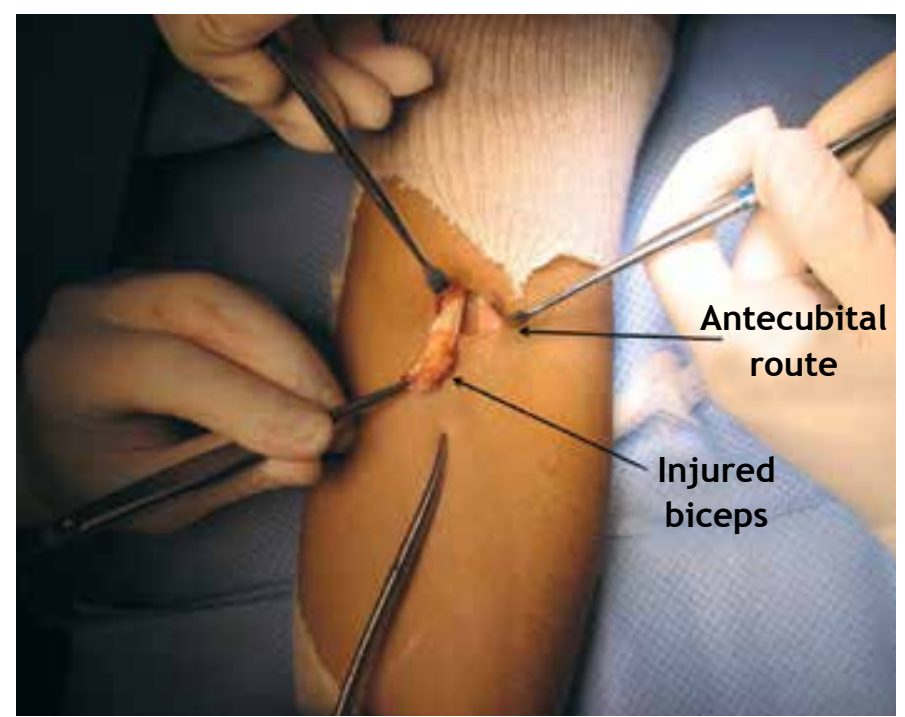

Figure 1 - Antecubital route.

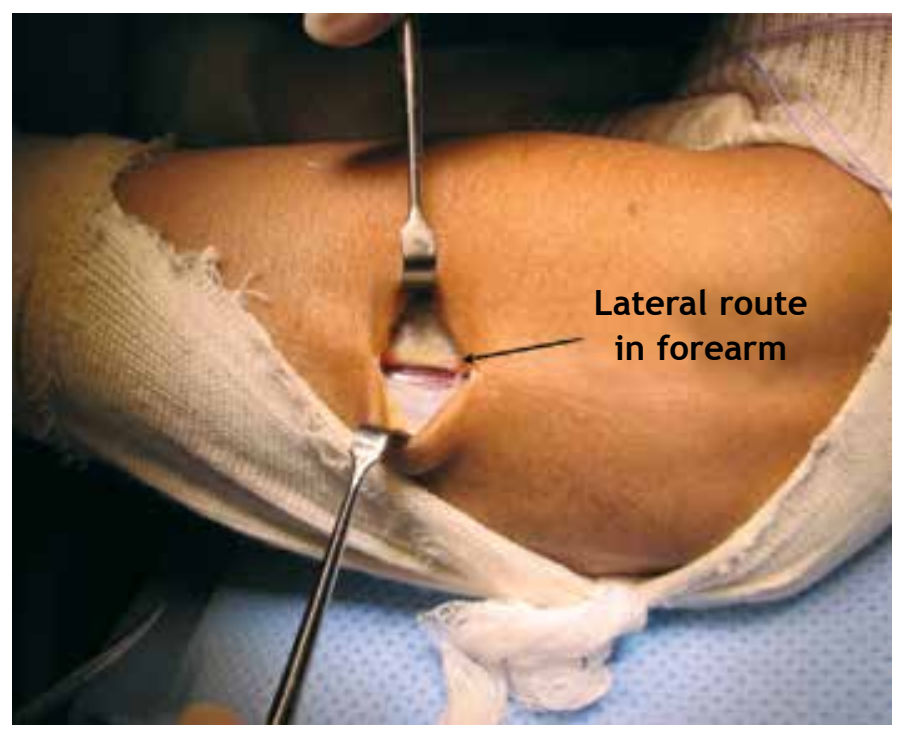

Figure 2 - Lateral route.

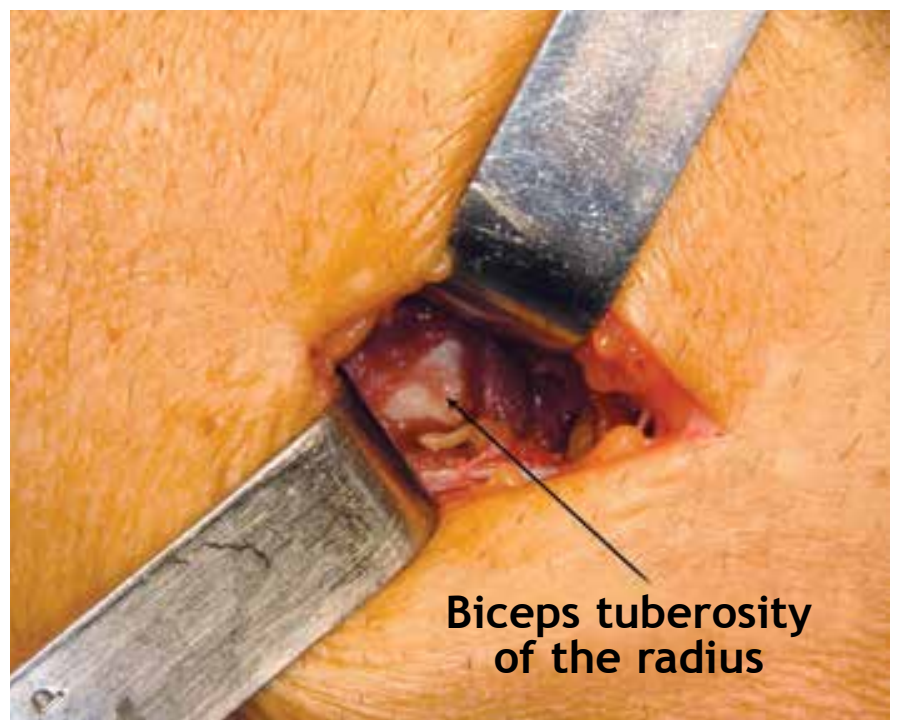

Figure 3 - Radial tuberosity, viewed through lateral route.

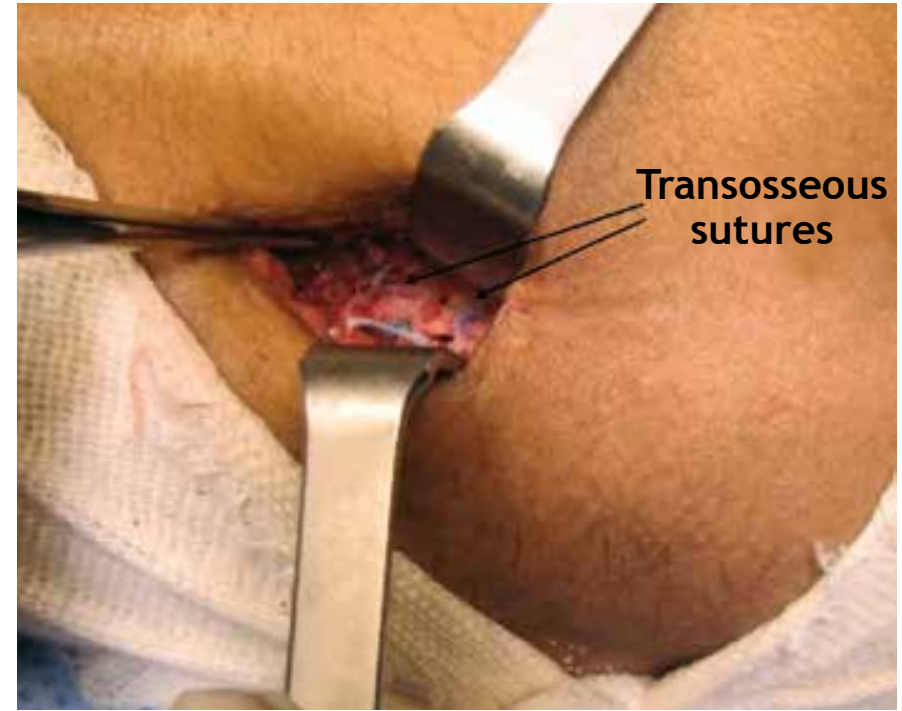

Figure 4 - Transosseous sutures.

biceps using a graft from the semitendinosus, as far as the insertion of the brachial muscle, since even with the graft it was not possible to reach the radial tuberosity. In this manner, the patient's aim of esthetic improvement was achieved, but without improvement of supination strength.

After the surgery, all the patients used a plaster-cast splint for one week, followed by use of a sling, and they were instructed to perform passive movement up to the pain threshold, for flexion-extension and pronation-supination. Two weeks after the surgery, the sling was removed and the patients were released to perform light activities such as lifting objects of the weight of a telephone, wallet, glass, etc. Physiotherapy was also started, in order to improve their passive range of motion, along with indirect isometric exercises (movements in which the biceps was the secondary motor). Four weeks after the operation, the patients started to perform isometric flexion-extension and pronation-supination work and, six weeks after the operation, isotonic work.

The four patients who required grafts were advised to delay removal of the sling for one week, and likewise to delay the start of physiotherapy.

The patients were assessed at least six months after the surgery. The following parameters were evaluated:

Mean DASH (Disabilities of the Arm, Shoulder and Hand)

\section{Mean Mayo Elbow Score}

- Digital dynamometry using Cybex ${ }^{\circledR}$ for flexion-extension (Figure 5) and pronation-supination (Figure 6) 


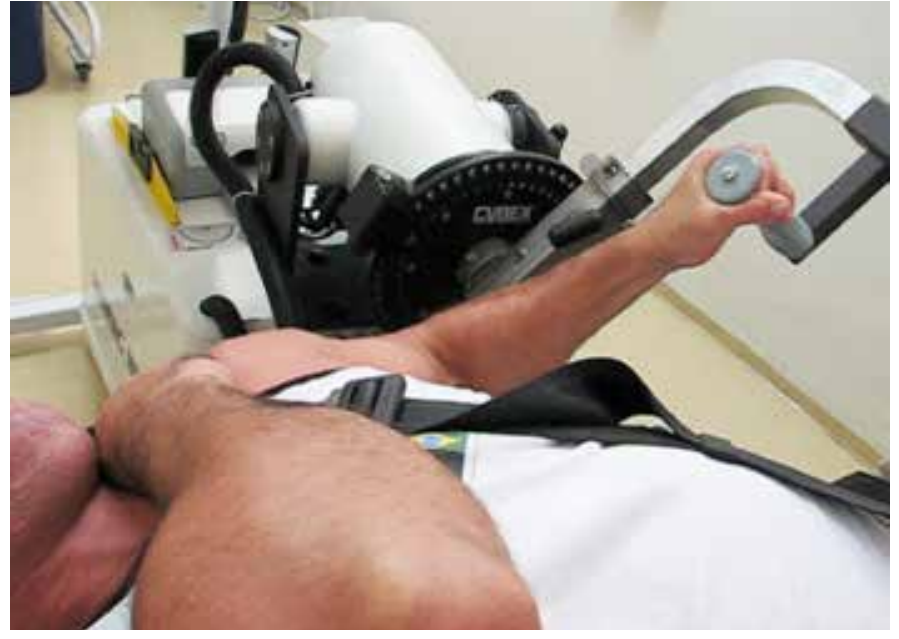

Figure 5 - Digital dynamometry for flexion-extension.

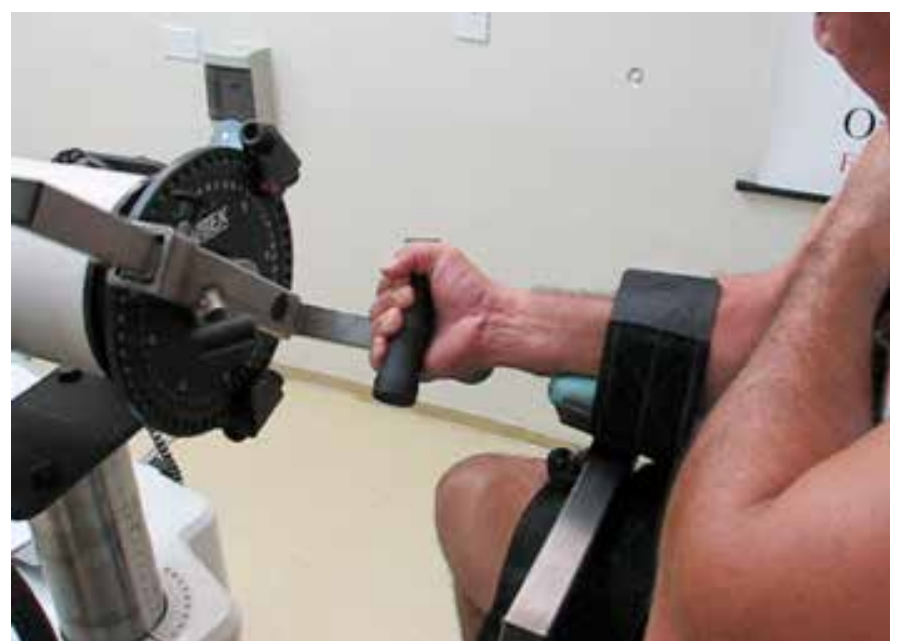

Figure 6 - Digital dynamometry for pronation-supination.

of the elbow, maintaining an angular velocity of $30 \%$, with five repetitions. This system measured:

a) Flexion: mean peak torque; mean deficit (operated side/normal side); mean deficit with correction (operated side with correction/normal side); Windsor mean; and mean without the patient debilitated.

b) Supination: mean peak torque; mean deficit (operated side/normal side); mean deficit (operated side with correction/normal side); Windsor mean; and mean without the patient debilitated.

- Digital dynamometry using Cybex ${ }^{\circledR}$ for flexionextension and pronation-supination of the elbow, maintaining an angular velocity of $120 \%$ s, with 15 repetitions. This system measured:

a) Flexion: mean peak torque; mean deficit (operated side/normal side); mean deficit with correction (operated side with correction/normal side).

b) Supination: mean peak torque; mean deficit (operaRev Bras Ortop. 2012;47(5):581-7 ted side/normal side); mean deficit with correction (operated side with correction/normal side).

The examination was bilateral and comparative. To evaluate pronation-supination, the patient was left with the elbow at $90^{\circ}$ in order roe void shoulder action.

To determine the deficit, the corrected deficit was applied with a correction factor of $10 \%$ for right-handed individuals and $0 \%$ for left-handed individuals, in accordance with the comparison standards established for upper limbs ${ }^{(23)}$. The simple deficit was also used, because there is still some debate in the literature regarding whether correction factors should be used ${ }^{(24)}$. - Goniometry:

\section{a) Mean loss of flexion-extension}

Mean and Windsor mean for loss of pronation-supination

The measurements of loss of flexion-extension and pronation-supination were made in comparison with the unaffected side, using the international standard for manual goniometry for each $5^{\circ}$, because the measurements were not made using digital goniometry.

The Windsor mean, or truncated mean, was used in certain cases because this is a statistical measurement of central trend that has the aim of extracting point distortions in small samples.

\section{RESULTS}

Between April 2006 and July 2011, 17 lesions of the distal biceps in male patients were operated using the Mayo mini-double route technique and assessed.

Of these patients, nine underwent the digital dynamometry examination using $\mathrm{Cybex}^{\circledR}$ and were analyzed in this study. Four of them needed grafts from the semitendinosus tendon. One patient who is currently undergoing prostate cancer treatment was debilitated but insisted on participating in the examination; however, he was only able to do the text at an angular velocity of $30 \%$ s.

The patients' mean age was 41.51 years (ranging from 33 to 70 years). The 70 -year-old patient (IJR) was operated 42 months earlier, and thus was 66 years of age at the time of the operation.

Three patients were operated on the right side and six on the left side. Four were operated on the non-dominant side and five on the dominant side.

The mean DASH was 9.25 and the mean Mayo Elbow Score was 95.56. The mean loss of range of motion was $0.5^{\circ}$ in relation to flexion-extension and 
$14.44^{\circ}$ in relation to pronation-supination. The Windsor mean for loss of pronation-supination was $5.71^{\circ}$.

The results from digital dynamometry showed:

1. With five repetitions at an angular velocity of $30^{\circ} / \mathrm{s}$.

a) Flexion: mean deficit of $9.6 \%$; mean corrected deficit of $7.03 \%$; and Windsor mean of $6.12 \%$. When the debilitated patient (IJR) was excluded, the mean was $3.40 \%$.

b) Supination: mean deficit of $-28.97 \%$; mean corrected deficit of $-29.89 \%$; and Windsor mean of $-30.32 \%$. When the debilitated patient was excluded, the mean was $-36.52 \%$.

2. Digital dynamometry using Cybex ${ }^{\circledR}$ for flexion and supination of the elbow, maintaining an angular velocity of $120^{\circ}$ s with 15 repetitions (the debilitated patient was unable to perform this test):

a) Flexion: mean deficit of $4.43 \%$; mean corrected deficit of $2.76 \%$.

b) Supination: mean deficit of $-24.1 \%$; mean corrected deficit of $-24.89 \%$.

The peak torque is detailed in Table 1.

\section{DISCUSSION}

The mechanism and physiopathology of lesions of the distal biceps are well established ${ }^{(24)}$. However, there are several possibilities for their surgical treatment. A single anterior route is most commonly associated with greater rates of neurological lesions, while the double route is associated with proximal radioulnar synostosis $^{(25)}$. However, recent studies have demonstrated greater safety with both approaches due to greater care and better familiarization with the regional anatomy among surgeons ${ }^{(26)}$. Several fixation methods for the biceps have also been reported ${ }^{(27)}$. The Endobutton ${ }^{\circledR}$ transcortical fixation method presents greater mechanical resistance, although there have been reports of losses and impact due to abrasion by the wires (which are at $180^{\circ}$ to the insertion of the biceps in the radius) with the edge of the ulna bone. Poor positioning of the Endobutton ${ }^{\circledR}$ may also cause loss of the surgery through loosening of the synthesis material ${ }^{(28)}$. Some studies have suggested the possibility that the posterior interosseous nerve might be injured at the exit point of the Endobutton ${ }^{\circledR(29)}$. Several biomechanical trials on the elbow have shown that anchors have less fixation strength $^{(30)}$. In the case of bioabsorbable anchors, there may also be radial osteolysis ${ }^{(31)}$. Interference screws enable good fixation, but over the long term they diminish the area of biological healing by around $50 \%$, since the region of screw insertion may not heal, as

Table 1. Table of results.

\begin{tabular}{|c|c|c|c|c|c|c|c|c|c|c|c|c|c|c|c|c|c|}
\hline \multirow{2}{*}{\begin{tabular}{l|} 
Name \\
DSOL
\end{tabular}} & \multirow{2}{*}{\begin{tabular}{|c|} 
Age \\
49 \\
\end{tabular}} & \multirow{2}{*}{\begin{tabular}{|c|} 
Time \\
23 \\
\end{tabular}} & \multirow{2}{*}{\begin{tabular}{|c|} 
Side \\
$\mathrm{R}$ \\
\end{tabular}} & \multicolumn{2}{|c|}{ Dominance } & \multirow{2}{*}{\begin{tabular}{|c|} 
Graft \\
$\mathrm{N}$ \\
\end{tabular}} & \multirow{2}{*}{\begin{tabular}{|c|}
$\begin{array}{c}\text { Flexion } \\
\text { rate } 30 \% / s \\
\text { injured }\end{array}$ \\
39
\end{tabular}} & $\begin{array}{c}\text { Flexion } \\
\text { rate } 30 \% / s \\
\text { normal }\end{array}$ & \multirow{2}{*}{\begin{tabular}{|c|}
$\begin{array}{c}\text { Loss } \\
\%\end{array}$ \\
2.5 \\
\end{tabular}} & \multirow{2}{*}{\begin{tabular}{|c|}
$\begin{array}{c}\text { Loss with } \\
\text { correction } \\
\%\end{array}$ \\
-3.23 \\
\end{tabular}} & $\begin{array}{l}\text { Loss \% } \\
\text { Windsor }\end{array}$ & \multirow{2}{*}{\begin{tabular}{|c|}
$\begin{array}{c}\text { Loss } \\
\%- \\
\text { IJR }\end{array}$ \\
-3.23 \\
\end{tabular}} & \multicolumn{2}{|c|}{$\begin{array}{c}\text { Flexion } \\
\text { rate } 120 \% \mathrm{~s} \\
\text { injured }\end{array}$} & \begin{tabular}{|c|} 
Flexion \\
rate \\
$120 \% \mathrm{~s}$ \\
normal \\
\end{tabular} & \multirow{2}{*}{$\begin{array}{c}\begin{array}{c}\text { Loss } \\
\%\end{array} \\
-9.68\end{array}$} & \multirow{2}{*}{\begin{tabular}{|c|}
$\begin{array}{c}\text { Loss with } \\
\text { correction } \\
\%\end{array}$ \\
1.29 \\
\end{tabular}} \\
\hline & & & & \multicolumn{2}{|c|}{$\mathrm{R}$} & & & 34 & & & -3.23 & & \multicolumn{2}{|l|}{34} & 31 & & \\
\hline IJR & 70 & 42 & $\mathrm{R}$ & \multicolumn{2}{|c|}{$\mathrm{R}$} & $S$ & 8.6 & 12.1 & 28.93 & 36.04 & & & & & & & \\
\hline LRM & 64 & 38 & $\mathrm{~L}$ & \multicolumn{2}{|c|}{$L$} & $\mathrm{~S}$ & 42 & 42 & 0 & 0 & 0 & 0 & \multicolumn{2}{|l|}{42} & 49 & 14.19 & 14.29 \\
\hline MORR & 33 & 6 & $\mathrm{~L}$ & \multicolumn{2}{|c|}{$\mathrm{R}$} & $\mathrm{N}$ & 39 & 50 & 22 & 14.2 & 14.2 & 14.2 & \multicolumn{2}{|l|}{27} & 39 & 30.77 & 23.85 \\
\hline MP & 55 & 39 & $\mathrm{R}$ & \multicolumn{2}{|c|}{$\mathrm{R}$} & $\mathrm{N}$ & 47 & 42 & -11 & -0.064 & -0.06 & \begin{tabular}{|l|l|}
4 & -0.064 \\
\end{tabular} & \multicolumn{2}{|l|}{46} & 38 & -21.1 & -8.95 \\
\hline RDM & 37 & 39 & $\mathrm{~L}$ & \multicolumn{2}{|c|}{$\mathrm{L}$} & $\mathrm{S}$ & 46 & 58 & 20.69 & 20.69 & $20.6 s$ & \begin{tabular}{|l|l|}
9 & 20.69 \\
\end{tabular} & \multicolumn{2}{|l|}{72} & 87 & 17.25 & 17.25 \\
\hline RMLP & 54 & 26 & $\mathrm{~L}$ & \multicolumn{2}{|c|}{$\mathrm{R}$} & $\mathrm{N}$ & 34 & 42 & 19.05 & 10.96 & 10.96 & 10.96 & \multicolumn{2}{|l|}{31} & 37 & 16.22 & 7.84 \\
\hline JBMC & 36 & 72 & $\mathrm{~L}$ & & $R$ & $\mathrm{~S}$ & 77 & 85 & 9.42 & 0.35 & 0.35 & 0.35 & 68 & & 77 & 11.69 & 2.86 \\
\hline VFD & 45 & 48 & $\mathrm{~L}$ & & $\mathrm{R}$ & $\mathrm{N}$ & 41 & 39 & -5.19 & -15.64 & & -15.64 & 57 & & 46 & -23.9 & -36.3 \\
\hline & 49.2 & 37 & & & & & 41.51111 & 44.9 & 9.6 & 7.034 & 6.1294 & \begin{tabular}{|l|l|}
429 & 3.4083 \\
\end{tabular} & 47.12 & & 50.5 & 4.435 & 2.76625 \\
\hline $\begin{array}{l}\text { Supina } \\
\text { rate } 3 c \\
\text { injur }\end{array}$ & $\begin{array}{l}\text { ation } \\
30 \% \mathrm{~s} \\
\text { red }\end{array}$ & $\begin{array}{r}\text { Supina } \\
\text { rate } 30 \\
\text { norm }\end{array}$ & $\begin{array}{l}\text { tion } \\
0 \% / \mathrm{s} \\
\text { nal }\end{array}$ & $\begin{array}{c}\text { Loss } \\
\%\end{array}$ & $\begin{array}{r}\text { Loss } \\
\text { correc } \\
\%\end{array}$ & $\begin{array}{l}\text { with } \\
\text { ction } \\
6\end{array}$ & $\begin{array}{l}\text { Windsor } \\
\text { mean } \%\end{array}$ & \begin{tabular}{|c|c} 
Loss \% \\
IJR
\end{tabular} & $\begin{array}{l}\text { upinatior } \\
\text { ate } 120 \% \text { s } \\
\text { injured }\end{array}$ & \begin{tabular}{c|c|}
$\mathrm{n}$ & Supination \\
$\mathrm{s}$ & rate $120 \% / \mathrm{s}$ \\
& normal
\end{tabular} & $\begin{array}{c}\text { Loss } \\
\%\end{array}$ & \begin{tabular}{|c|} 
Loss with \\
correction \\
$\%$
\end{tabular} & DASH & MES & \begin{tabular}{c|c|} 
S & Loss \\
F/E
\end{tabular} & $\begin{array}{l}\text { Loss } \\
\text { P/S }\end{array}$ & $\begin{array}{l}\text { Windsor } \\
\text { mean }\end{array}$ \\
\hline 8 & & 4 & & -100 & -80 & & & -80 & 7 & 3 & -133 & -110 & 0.5 & 100 & 0 & 0 & 0 \\
\hline 3.5 & & 4.2 & & 16.67 & 23.1 & & & & & & & & 50 & 90 & 0 & 0 & 0 \\
\hline 14 & & 11 & & -27.27 & -27.2 & & -27.27 & -27.27 & 12 & 11 & -9.09 & -9.09 & 9 & 85 & 0 & 90 & \\
\hline 5 & & 5 & & 0 & -10 & & -10 & -10 & 4 & 5 & 20 & 12 & 2.5 & 100 & 0 & 0 & 0 \\
\hline 11 & & 7 & & -57.14 & -41. & & -41.42 & -41.42 & 9 & 7 & -28.57 & -15.71 & 9.1 & 100 & 5 & 15 & 15 \\
\hline 7 & & 8 & & 12.5 & 12. & & 12.5 & 12.5 & 7 & 7 & 0 & 0 & 2.5 & 100 & 0 & 0 & 0 \\
\hline 7 & & 7 & & 0 & -10 & & -10 & -10 & 4 & 7 & 42.86 & 37.15 & 7.5 & 85 & 0 & 25 & 25 \\
\hline 16 & & 11 & & -45.45 & -60 & & -60 & -60 & 15 & 12 & -25 & -37.5 & 0.5 & 100 & 0 & 0 & 0 \\
\hline 8 & & 5 & & -60 & -76 & & -76 & -76 & 8 & 5 & -60 & -76 & 1.7 & 100 & 0 & 0 & \\
\hline 8.833 & 333 & 6.911 & & 28.966 & -29.8 & & -30.312857 & -36.52 & 8.25 & 7.125 & -24.1 & -24.89375 & \begin{tabular}{|l|}
9.256 \\
\end{tabular} & 95.6 & \begin{tabular}{|l|l|}
5 & 0.5556 \\
\end{tabular} & 14.444 & 5.714286 \\
\hline
\end{tabular}


well as possibly causing osteolysis. The technique of using interference screws in association with Endobutton ${ }^{\circledR}$ is the method that presents greatest resistance to traction $^{(27)}$, but it has the same problems as shown in using interference screws and Endobutton ${ }^{\circledR}$ separately.

Transosseous stitches ${ }^{(22)}$ have demonstrated satisfactory results in our experience, although they present lower fixation strength than shown by Endobutton ${ }^{\circledR}$ and interference screws. On the other hand such stitches have the advantage of being more biological and cheaper. One of the contraindications of transosseous stitches is osteoporotic bone, and in such cases the best option is Endobutton ${ }^{\circledR(28)}$. Our results from evaluating Cybex ${ }^{\circledR}$ showed that this surgical procedure improved the specific performance for flexion and supination, and that for elderly and osteoporotic patients, the losses in these parameters were acceptable and often unnoticed. Thus, the indication among elderly and osteoporotic patients is debatable. We performed two operations on patients over the age of 60 years who were doing physical exercises in gyms on a regular basis, and one of them was even participating in basic weightlifting championships.

Our preference is the Mayo mini-double route described by Morrey et a ${ }^{(22)}$, using transosseous stitches, given that we have not had any losses from the 17 operations followed up that we have so far performed using this technique. This is despite the high functional demands of some of the patients: one was a player in the Brazilian national rugby team, one was a basic master weightlifter, two were professional jiu-jitsu players, one was a freestyle wrestler, two were doing muscle-building exercises, one was a professional bodybuilder and one was an abseiling instructor.

In our opinion, Endobutton ${ }^{\circledR}$ may be the best option in cases of surgical reconstruction using transosseous stitches.

Use of grafts, when necessary, has been reported in several studies. Our preference is for the semitendinosus because of the vast range of studies relating to its resistance to tension in knee ligament reconstructions, its ease of harvesting and the lack of grafts from cadavers in Brazil.

The loss of range of motion was not significant for flexion, but was significant for supination because of one patient who had a deficit of around $90^{\circ}$, with a range of $40^{\circ}$ for pronation and $40^{\circ}$ for supination, while his contralateral angles were respectively 90 and $80^{\circ}$. This patient required a graft and underwent the operation more than two years after injury. Because this was an isolated case, the Windsor mean, which corrects distortions by giving the sample a more central trend and eliminating the best and worst results from the series, was used to correct this distortion in the sample, such that the measured loss of pronation-supination of the group fell from $14.44^{\circ}$ to $5.71^{\circ}$. These data demonstrate that even if the loss of range of motion is insignificant, it may be a complication of the surgery. Nonetheless, this patient said that he was satisfied with the surgical procedure.

The losses of strength relating to unrepaired lesions of the distal biceps reach $30 \%$ for flexion and $40 \%$ for supination ${ }^{(24)}$. An improvement in flexion strength rates through the surgery was expected in the present study, but supination presented results beyond what was expected ${ }^{(32)}$.

The literature also shows that reconstruction is associated with better results for supination in subjective examinations, but few studies have demonstrated this objectively, though digital dynamometry.

One important finding was that the gain in supination strength was greater than expected, and this may have been due to the rigid and accelerated protocol used in the rehabilitation. This gain was effective in training specific movements that the patients possibly were not doing before their injuries. It has been recognized that accelerated protocols bring benefits in terms of early mobilization in cases of tendon repair ${ }^{(33)}$.

Our sample was relatively small, like in all other published papers relating to this type of injury, which is considered to be of low prevalence.

Our results follow the trend in the literature, showing an improvement in strength parameters that was associated with high degrees of satisfaction ${ }^{(22,23,26,28,32)}$.

The functional losses do not justify surgery among patients with low demand. Surgery is indicated for athletes, young patients, those with high functional demands and those who do not accept the loss of strength or esthetic deformity.

\section{CONCLUSION}

The technique of transosseous reinsertion by means of the Mayo mini-double route for treating lesions of the distal biceps was shown to be a safe and low-cost method, with few complications and good functional results. 


\section{REFERENCES}

1. Gilcreest ED. Rupture of muscles and tendons particularly subcutaneous rupture of the biceps flexor cubiti. J Am Med Assoc. 1925;84(24):1819-22.

2. Baker BE, Bierwagen D. Rupture of the distal tendon of the biceps brachii. Operative versus non-operative treatment. J Bone Joint Surg Am. 1985;67(3):414-7.

3. Boyd HB, Anderson LD. A method for reinsertion of the distal biceps brachi tendon. J Bone Joint Surg Am. 1961;43:1041-43.

4. Mazzocca AD, Cohen M, Berkson E, Nicholson G, Carofino BC, Arciero R Romeo AA. The anatomy of the bicipital tuberosity and distal biceps tendon. $J$ Shoulder Elbow Surg. 2007;16(1):122-7.

5. O'Driscoll SW, Goncalves LB, Dietz P. The hook test for distal biceps tendon avulsion. Am J Sports Med. 2007;35(11):1865-9.

6. Balabaud L, Ruiz C, Nonnenmacher J, Seynaeve P, Kehr P, Rapp E. Repair of distal biceps tendon ruptures using a suture anchor and an anterior approach. J Hand Surg Br. 2004;29(2):178-82.

7. Bain GI, Johnson LJ, Turner PC. Treatment of partial distal biceps tendon tears. Sports Med Arthrosc. 2008;16(3):154-61.

8. Bisson LJ, de Perio JG, Weber AE, Ehrensberger MT, Buyea C. Is it safe to perform aggressive rehabilitation after distal biceps tendon repair using the modified 2-incision approach? A biomechanical study. Am J Sports Med 2007;35(12):2045-50.

9. Khan W, Agarwal M, Funk L. Repair of distal biceps tendon rupture with the Biotenodesis screw. Arch Orthop Trauma Surg. 2004;124(3):206-8.

10. Peeters T, Ching-Soon NG, Jansen N, Sneyers C, Declercq G, Verstreken F. Functional outcome after repair of distal biceps tendon ruptures using the endobutton technique. J Shoulder Elbow Surg. 2009;18(2):283-7.

11. Sethi P, Cunningham J, Miller S, Sutton KM, Mazzocca AD.Anatomic repair of the distal biceps tendon using the tension-slide technique. Tech Shoulder Elbow Surg. 2008;9:182-97.

12. An KN, Hui FC, Morrey BF, Linscheid RL, Chao EY. Muscles across the elbow joint: a biomechanical analysis. J Biomech. 1981;14(10):659-69.

13. Greenberg JA, Fernandez JJ, Wang T, Turner C. EndoButton-assisted repair of distal biceps tendon ruptures. J Shoulder Elbow Surg. 2003;12(5):484-90.

14. Kettler M, Tingart MJ, Lunger J, Kuhn V. Reattachment of the distal tendon of biceps: factors affecting the failure strength of the repair. $J$ Bone Joint Surg Br. 2008;90(1):103-6.

15. Wiley WB, Noble JS, Dulaney TD, Bell RH, Noble DD. Late reconstruction of chronic distal biceps tendon ruptures with a semitendinosus autograft technique. J Shoulder Elbow Surg. 2006;15(4):440-4.

16. Sethi PM, Tibone JE. Distal biceps repair using cortical button fixation.Sports Med Arthrosc. 2008;16(3):130-5.

17. Spang JT, Weinhold PS, Karas SG. A biomechanical comparison of EndoButton versus suture anchor repair of distal biceps tendon injuries. J Shoulder Elbow Surg. 2006;15(4):509-14.
18. Kulshreshtha R, Singh R, Sinha J, Hall S. Anatomy of the distal biceps brachii tendon and its clinical relevance. Clin Orthop Relat Res. 2007;(456):117-20.

19. Hartman MW, Merten SM, Steinmann SP. Mini-open 2-incision technique for repair of distal biceps tendon ruptures. J Shoulder Elbow Surg. 2007;16(5):616-20.

20. Kelly EW, Morrey BF, O'Driscoll SW. Complications of repair of the distal biceps tendon with the modified two-incision technique. J Bone Joint Surg Am. 2000;82(11):1575-81.

21. El-Hawary R, Macdermid JC, Faber KJ, Patterson SD, King GJ. Distal biceps tendon repair: comparison of surgical techniques. J Hand Surg Am. 2003;28(3):496-502.

22. Morrey BF, Askew LJ, An KN, Dobyns JH. Rupture of the distal tendon of the biceps brachii. A biomechanical study. J Bone Joint Surg Am. 1985;67(3):418-21.

23. Crosby CA, Wehbé MA, Mawr B. Hand strength: normative values. J Hand Surg Am. 1994;19(4):665-70.

24. Wittstein J, Queen R, Abbey A, Moorman CT 3rd. Isokinetic testing of biceps strength and endurance in dominant versus nondominant upper extremities. J Shoulder Elbow Surg. 2010;19(6):874-7.

25. Failla JM, Amadio PC, Morrey BF, Beckenbaugh RD. Proximal radioulnar synostosis after repair of distal biceps brachii rupture by the two-incision technique. Report of four cases. Clin Orthop Relat Res. 1990;(253):133-6.

26. Keener JD. Controversies in the surgical treatment of distal biceps tendon ruptures: single versus double-incision repairs. J Shoulder Elbow Surg. 2011;20(Suppl 2):S113-25.

27. Siebenlist S, Lenich A, Buchholz A, Martetschläger F, Eichhorn S, Heinrich $\mathrm{P}$, et al.Biomechanical in vitro validation of intramedullary cortical button fixation for distal biceps tendon repair: a new technique. Am J Sports Med. 2011;39(8):1762-8.

28. Peeters T, Ching-Soon NG, Jansen N, Sneyers C, Declercq G, Verstreken F. Functional outcome after repair of distal biceps tendon ruptures using the endobutton technique. J Shoulder Elbow Surg. 2009;18(2):283-7

29. Lo EY, Li CS, Van den Bogaerde JM. The effect of drill trajectory on proximity to the posterior interosseous nerve during cortical button distal biceps repair. Arthroscopy. 2011;27(8):1048-54.

30. Ahmad CS, Lee TQ, EIAttrache NS. Biomechanical evaluation of a new ulnar collateral ligament reconstruction technique with interference screw fixation. Am J Sports Med. 2003;31(3):332-7.

31. Potapov A, Laflamme YG, Gagnon S, Canet F, Rouleau DM. Progressive osteolysis of the radius after distal biceps tendon repair with the bioabsorbable screw. J Shoulder Elbow Surg. 2011;20(5):819-26.

32. Davison BL, Engber WD, Tigert LJ. Long term evaluation of repaired distal biceps brachii tendon ruptures. Clin Orthop Relat Res. 1996;(333):186-91.

33. Kelly EW, Steinmann S, O'Driscoll SW. Surgical treatment of partial distal biceps tendon ruptures through a single posterior incision. J Shoulder Elbow Surg. 2003;12(5):456-61. 